\title{
LIDAR MEASUREMNT ON DUST TRANSPORT FROM THE SAHARAN DESERT TO THE IRAN PLATEAU
}

\author{
Hossein Panahifar ${ }^{1 *}$, Ruhollah Moradhaseli ${ }^{3}$, Hadi Bourzoie ${ }^{4}$, Mahdi Gholami ${ }^{1}$, Hamid Reza \\ Khalesifard ${ }^{1,2}$ \\ ${ }^{1}$ Department of Physics, and ${ }^{2}$ Research Center for Climate Change and Global Warming, Institute for \\ Advanced Studies in Basic Sciences, 4513766731 Zanjan, Iran \\ ${ }^{3}$ Physics Department, Faculty of Science, Zanjan Branch, Islamic Azad University, Zanjan, Iran \\ ${ }^{4}$ Faculty of Engineering, Sabzevar University of New Technology, 9615131113 Sabzevar, Iran \\ *Email: h.panahifar@iasbs.ac.ir
}

\begin{abstract}
Optical properties of long-range Saharan dust particles transported to the Iran Plateau have been investigated. The results were derived from the measurements of a dual-wavelength Depolarized backscatter/Raman lidar and a Cimel CE318-2 sunphotometer. Observations were performed in Zanjan, Northwest Iran. The backward trajectory analysis show that the lofted dust plumes come from the Saharan desert and travel along Mediterranean Sea and Turkey toward Iran. The lidar ratio within the lofted dust layer has been found with mean values of $50 \mathrm{sr}$ at $532 \mathrm{~nm}$. For the depolarization ratio, mean values of $25 \%$ have been found.
\end{abstract}

\section{INTRODUCTION}

Atmospheric mineral dust can be transported more than tens of thousands of kilometers away from its sources in the free troposphere [1-3]. Dust is an important component of the atmospheric aerosol system and sensitively influences environmental and climatic conditions on the regional and global scales especially in northern hemisphere $[4,5]$. The Saharan desert as a main part of the dust belt, is the world largest mineral dust source [6,7]. The Iran Plateau $\left(\sim 26^{\circ}-36^{\circ} \mathrm{N}, \sim 45^{\circ}-61^{\circ} \mathrm{E}\right)$ which lies in the middle of the global dust belt is frequently affected by local, regional and trans-regional dust storm outbreaks.

Up to now, few works have been done to characterize the atmospheric aerosol properties as well as their transport scheme over the Iran Plateau. Khalesifard et al. installed a depolarized lidar to investigate the atmosphere above Tehran, the capital of Iran. They have shown that the urban pollution and polluted dust are the dominant contributors to the atmospheric aerosol burden most of the time, especially during the cold season. Dust particles are also the dominant atmospheric aerosol fraction during the warm season $[8,9]$. Panahifar et al. have reported a long-range dust transport from Arabian Peninsula to Tehran, Iran [10]. Bayat et al. and Masoumi et al. used a sunphotometer and measured column integrated aerosol properties for the atmosphere over Zanjan. They characterized the Mesopotamian region as the most influencing dust source over the measurement site $[11,12]$. Vishkaee et al. used a backscatter lidar to investigate some cases for transport of dust to Northwest of Iran during summer and winter times. They reported the Tigris and Euphrates basin and a dry region between the Aral and Caspian seas as sources for the mentioned cases [13]. There are also a few reports that are mentioning some parts of the Iran Plateau as sources for dust events. [3, 6].

This article provides a scenario of long-range dust transport from Northern Africa to Iran. In Sect. 2 the measurement site, the used lidar system, and the used auxiliary data are described. Sect. 3 gives an overview of the observations and two case studies are presented in detail. The conclusions are discussed in Sect. 4.

\section{INSTRUMENTATION AND MEASUREMENTS}

The IASBS Remote sensIng Station (IRIS) in Zanjan is equipped with a Depolarized backscatter /Raman lidar and a Cimel CE318-2 sun-photometer (SPM) [11]. Both instruments are deployed at the IASBS Physics Department building $\left(36.70^{\circ} \mathrm{N}\right.$, $48.51^{\circ} \mathrm{E}, 1800 \mathrm{~m}$ above mean sea level (amsl)). The lidar, has a frequency doubled pulsed Nd-YAG laser (pulse duration: $10 \mathrm{~ns}$, energy per pulse: 150 mJ@1064 nm and130mJ@532 nm)with a linear polarized output, as its transmitter. The detection 
unit after a 11" Schmidt-Cassegrain telescope can separate the parallel and cross-polarized signal components at $532 \mathrm{~nm}$. Further measurement channels collect lidar return signals at $607 \mathrm{~nm}$ (nitrogen Raman channel) and $1064 \mathrm{~nm}$ (elastic backscatter). The basic temporal and spatial signal resolution, with which the raw signals are stored, is $60 \mathrm{~s}$ and $7.5 \mathrm{~m}$, respectively. Figure 1 shows schematic diagram of the IRIS lidar setup.

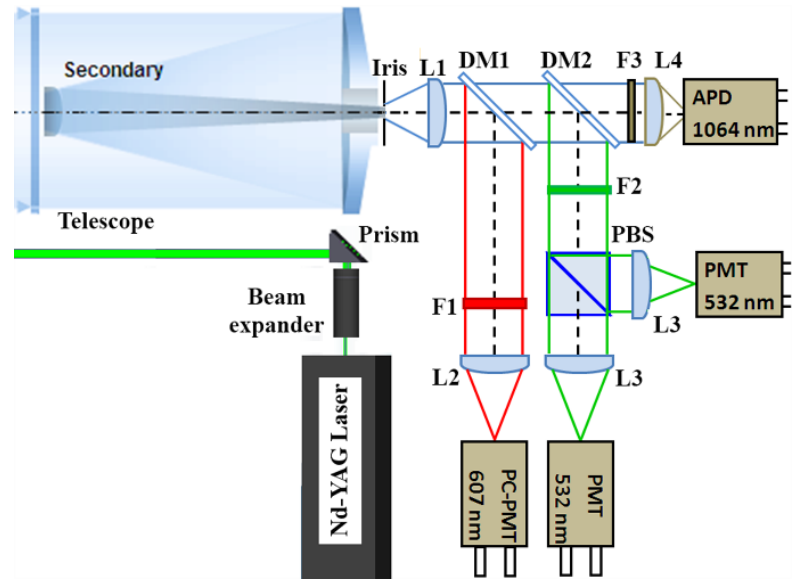

Figure 1 IRIS Polarization/Raman lidar setup

The particle backscatter coefficient at $532 \mathrm{~nm}$, the particle extinction coefficient at $532 \mathrm{~nm}$ and the respective particle extinction-to-backscatter ratio (lidar ratio) at $532 \mathrm{~nm}$ are determined from the elastic and inelastic return signals in the way described by Ansmann et al. [14]. Aerosol Optical Depth (AOD) at $550 \mathrm{~nm}$ taken from the Moderate Resolution Imaging Spectroradiometer (MODIS) Deep Blue collection (MOD08, MYD08) available from the Giovanni Web portal (http://disc.sci.gsfc.nasa.gov/giovanni). The Backtrajectories are calculated with the NOAA HYSPLIT model [15].

\section{RESULTS}

In the following two cases which are representing trans-continental dust transport from the Saharan desert to Zanjan area have been presented.

\section{1 Case I, 20-22 January 2019}

Figure 2 shows the time-height series of volume linear depolarization ratio (VLDR) at $532 \mathrm{~nm}$ recorded in Zanjan from 06:40 UTC, 20 January to 06:00 UTC, 22 January 2019. Fig. 2 demonstrates that the depolarization for the boundary layer varies between $10 \%-15 \%$ that can be due either to urban pollution or to temporally happening fog layers over the ground surface.

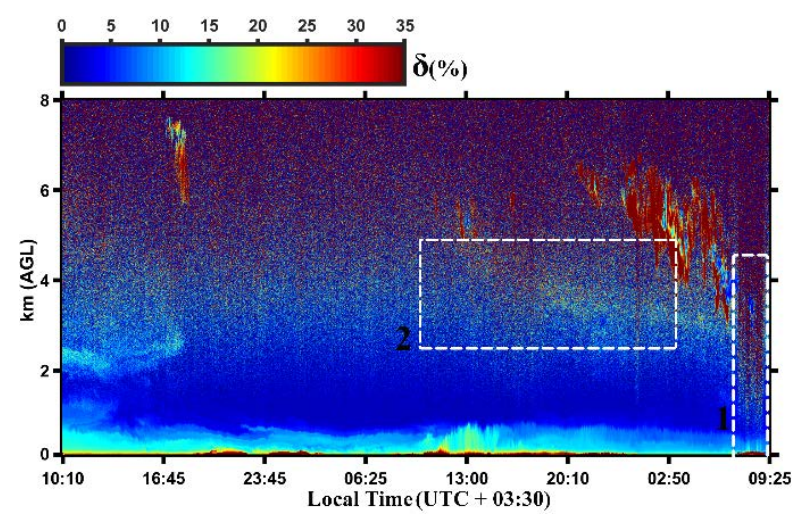

Figure 2 Time evolution of volume depolarization ratio between 06:40 UTC on 20 January 2019 and 06:00 UTC on 22 January 2019.

The Fig. 2 illustrate that at the last 2 hours of the time series (Dashed rectangle 1) the laser beam was obstructed by a dense layer of fog near the ground level and depolarization ratio increased probably due to multiple scattering (VLDR 35\%) [16]. A layer of lofted dust $(20 \% \leq \mathrm{VLDR} \leq 30 \%)$ can be seen around $4 \mathrm{~km}$ agl (Dashed rectangle 2). The layer spans from 09:30 UTC on 21 January 2019 until the early hour of next day.

The HYSPLIT 96 hour backward trajectories in Figure 3 demonstrate that the observed lofted dust layer (Fig. 2) is transported to Zanjan from North Africa. The backward trajectories that are starting from IRIS on 21 January 2019 at altitudes of 5 and $4.5 \mathrm{~km}$ agl, returning back to the south of Algeria and north of Niger respectively (Fig. 3). The air parcels travel over Mediterranean Sea, pass along Turkey-Syria border and eventually reach to the IRIS.

\section{2 Case II, 07-08 April 2013}

Figure 4 represents the temporal development of the attenuated backscatter ratio at $1064 \mathrm{~nm}$ channel recorded from 09:30 UTC, 07 April to 06:30 UTC, 08 April 2013. Black area denotes periods where no measurements were performed.

The mean (Maximum) AOD variations at $440 \mathrm{~nm}$, recorded on the SPM, during 07-08 April 2013 reaches to $0.25(0.35)$. 


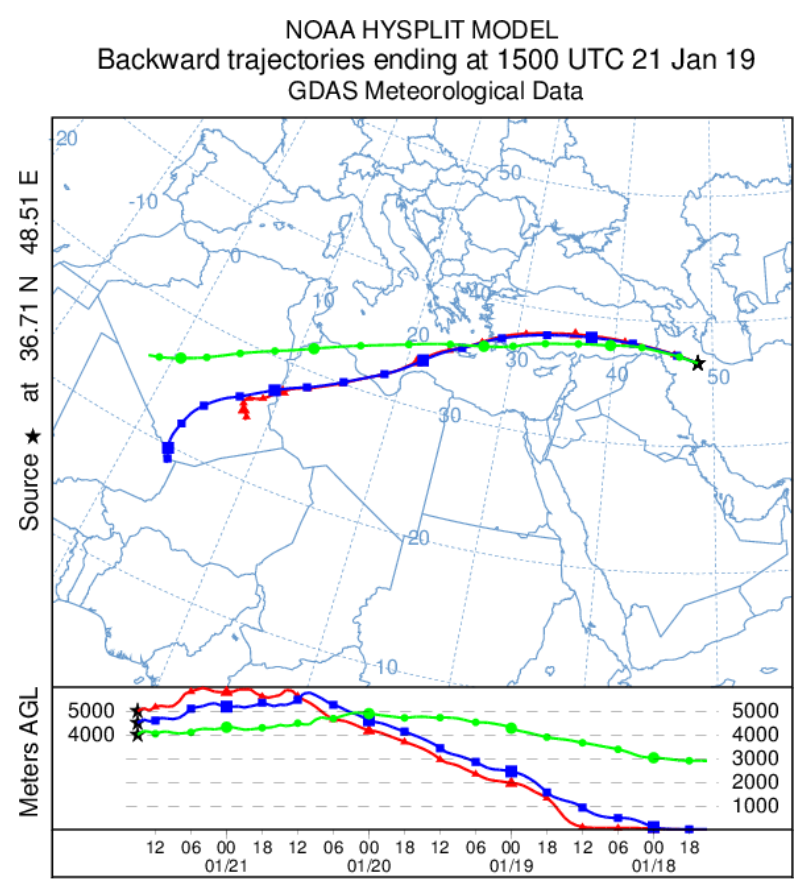

Figure 396 h HYSPLIT backward trajectories arriving to Zanjan on 15:00 UTC, 21 January 2019 at 5, 4.5 and $4 \mathrm{~km}$ heights agl.

The retrieved Ångström Exponent from the SPM data is obtained as $0.35 \pm 0.1$ for the mentioned date which corresponds to existence of particles in coarse mode. Fig. 4 depicts a lofted layer of Saharan dust that arrives over Zanjan at $~ 20: 00$ UTC on 07 April 2013 at altitudes 3-4 km agl. At the following times, beneath this layer, a thinner dust layer is recorded at altitudes around $2 \mathrm{~km} \mathrm{agl}$ (Fig. 5c). Vertical profiles of the optical properties of these dust layers are shown in Figure 5. The average (maximum) value of the particle linear depolarization ratio at $532 \mathrm{~nm}$ for the recorded layer at $\sim 4 \mathrm{~km}$ is obtained as $25 \%(30 \%)$.

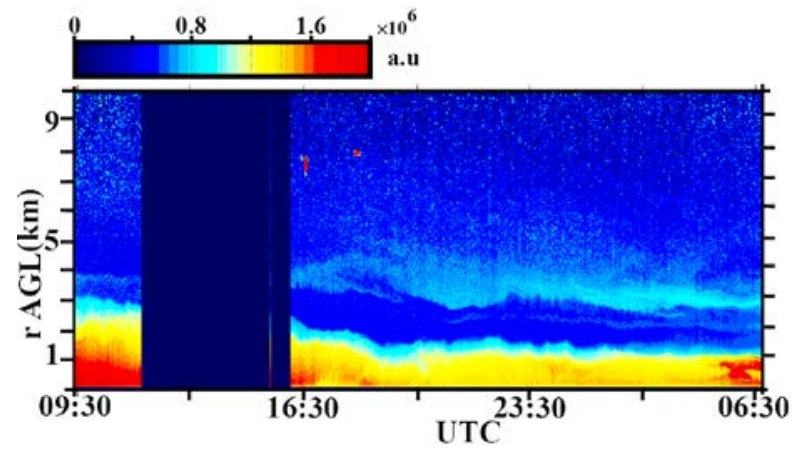

Figure 4 Time-height series of lidar attenuated backscatter profile recorded in Zanjan at $1064 \mathrm{~nm}$ between 09:30 UTC on 07 April 2013 and 06:30 UTC on 08 April 2013.

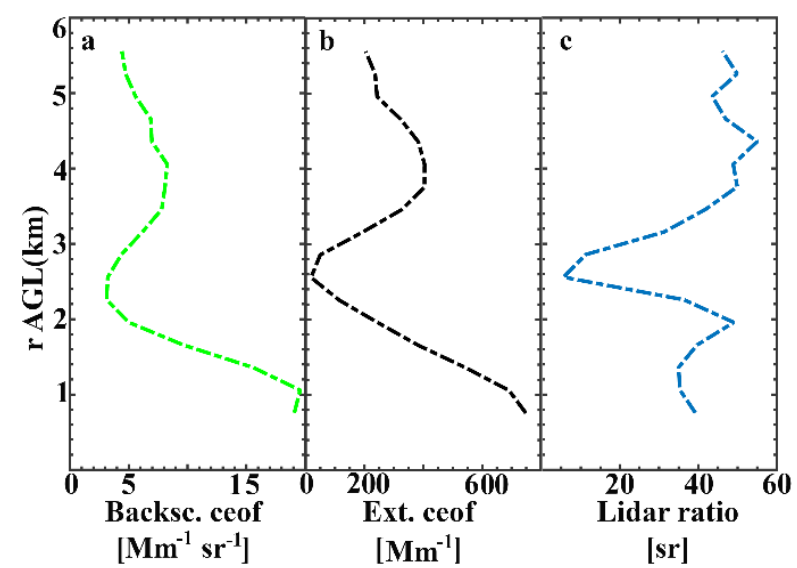

Figure 5 The averaged lidar profiles of a) Particle backscatter coefficient b) Particle extinction coefficient c) lidar ratio at $532 \mathrm{~nm}$ recorded during 19:40 UTC, 07 April 2013 to 01:30 UTC, 08 April 2013.

Fig. $5 \mathrm{c}$ depicts the mean lidar ratio values for this layer as $50.2 \mathrm{sr}$ at $532 \mathrm{~nm}$ and its maximum reaches to 55 sr. These values are comparable with previously reported lidar ratios for transported Saharan dust to European regions [17].

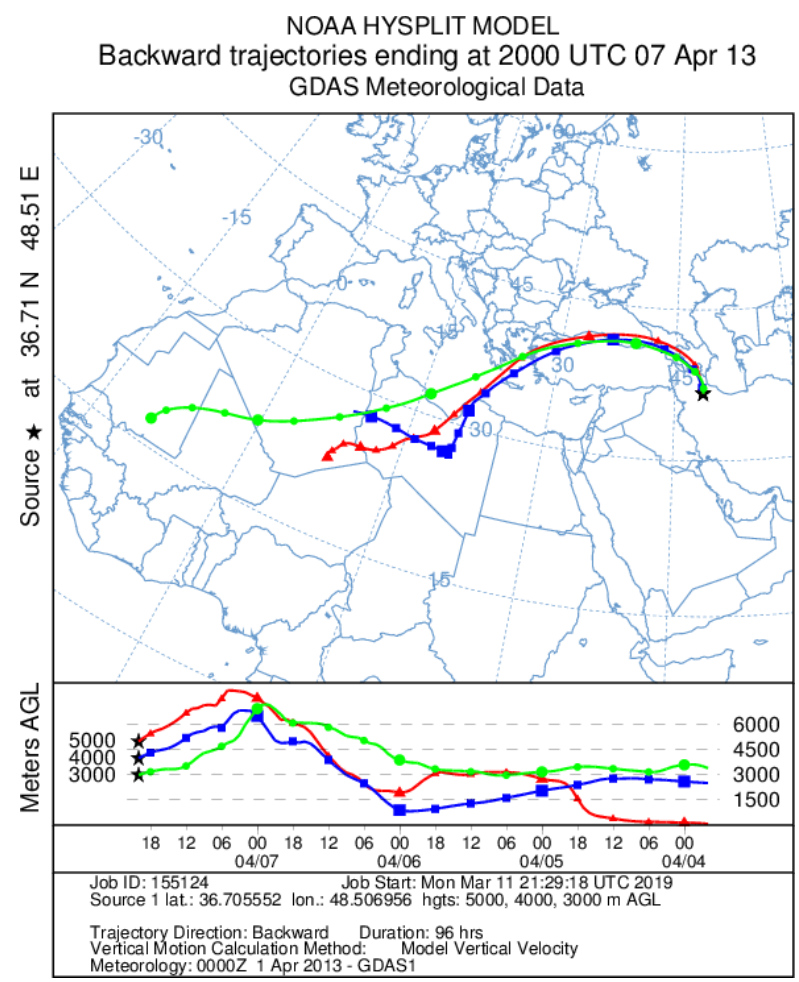

Figure 696 h HYSPLIT backward trajectories arriving at Zanjan on 20:00 UTC at 3, 4 and $5 \mathrm{~km}$ height.

Figure 6 shows the 96 hours HYSPLIT backward trajectories calculated for arrival heights of 5, 4 and $3 \mathrm{~km}$ agl starting from the IRIS. These heights are chosen based on the layer parameters that are 
represented in Figs. 5a-5c. Fig. 7 shows that the dust plume originates from Algeria and Niger, travels along the Mediterranean Sea, passes over Turkey and finally reaches to Zanjan. This behavior is very similar to Case I.

Figure 7 demonstrates MODIS derived daily Terra AOD Deep blue on 04 April 2013. Fig. 7 is corroborated by Fig. 6 and shows that AOD increased (AOD 1) over Niger.

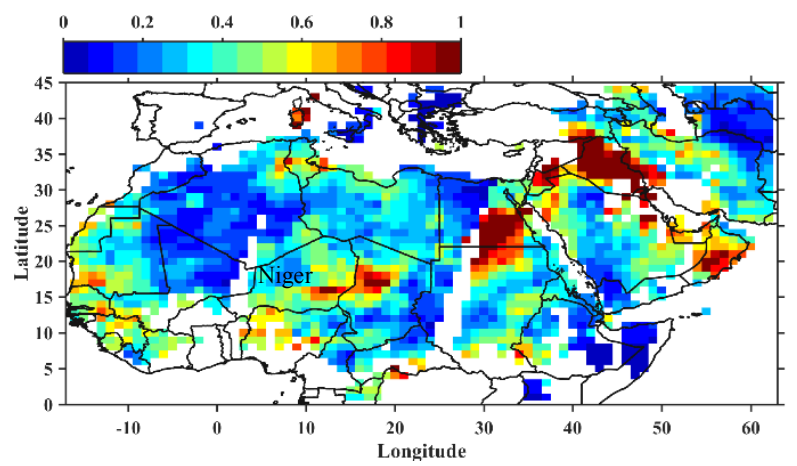

Figure 7 MODIS Terra daily AOD at $550 \mathrm{~nm}$ for 04 April 2013, Deep blue AOD for land surfaces.

\section{CONCLUSION}

We presented two cases where the Saharan dust transported across the Mediterranean Sea and reached to Northwest Iran. The extinction coefficient, the lidar ratio and the particle linear depolarization ratio have been calculated. The lofted Saharan dust layers are recorded at height between $3-5 \mathrm{~km}$ agl for both cases. The measured depolarization ratios for both cases range between $20 \%$ to $30 \%$ at $532 \mathrm{~nm}[18,19]$. Mean values of the lidar ratio of the long-range transported Saharan dust (07 April 2013) are $50 \mathrm{sr}$ at $532 \mathrm{~nm}$. These lidar ratio value is comparable with typical lidar ratios of the Saharan dust (50-60 sr) and higher than lidar ratios of dust from Middle East (35-45 sr) [17-19]. According to HYSPLIT backward trajectories, for both cases, the lofted dust layer originates from the Saharan desert and travel over Mediterranean Sea and could not mix with dust from Mesopotamia and the Arabian Peninsula.

\section{ACKNOWLEDGEMENTS}

The authors would like to appreciate the NOAA Air Resources Laboratory (ARL) for the provision of the HYSPLIT transport model. The MODIS mission scientists and associated NASA personnel is acknowledged for the production of the data used in this research effort.

\section{REFERENCES}

[1] Haarig et al., Atmospheric Chemistry and Physics 17, p.10767 (2017)

[2] Mamouri, Rodanthi-Elisavet, et al. Atmospheric Chemistry and Physics 16.21 (2016): 13711-13724

[3] Hofer, Julian, et al. Atmospheric Chemistry and Physics 17.23 (2017): 14559

[4] Myhre, G. and Stordal, J. Geophys. Res., 106, 18193-18204 (2001)

[5] Balkanski, Y., et al. Atmospheric Chemistry and Physics 7.1 (2007): 81-95

[6] Prospero, Joseph M., et al. Reviews of geophysics 40.1 (2002): 2-1

[7] Liu, Xiaohong, et al. Atmospheric Chemistry and Physics 11.15 (2011): 7781

[8] Khalesifard, Hamid Reza, and Hossein Panahifar, Optics and Photonics for Energy and the Environment. Optical Society of America, 2015

[9] Panahifar, Hossein, and Hamid Khalesifard. EPJ Web of Conferences. Vol. 176. EDP Sciences, 2018

[10] Panahifar et al. to be appear in Central Asian Dust Conference (CADUC 2019), Dushanbe, Tajikistan

[11] Bayat, Ali, et al. Atmospheric Measurement Techniques 6.10 (2013): 2659-2669

[12] Masoumi, A., et al. Atmospheric research 120 (2013): 343-355

[13] Abdi Vishkaee, Farhad, et al. Journal of Geophysical Research: Atmospheres 117.D3 (2012)

[14] Ansmann, Albert, et al. Appl. Opt., 31, 7113-7131, 1992

[15] Stein, A. F., et al. Bulletin of the American Meteorological Society 96.12 (2015): 2059-2077

[16] Weitkamp, Claus, ed. Springer Science \& Business, 2006

[17] Nisantzi, Argyro, et al. Atmospheric Chemistry and Physics 15.12 (2015): 7071-7084

[18] Groß, S., et al. Atmospheric Chemistry and Physics 19 (2015): 11067-11080

[19] Tesche, Matthias, et al. Chemical and Physical Meteorology 61.1 (2009): 144-164 